\title{
COMPETITIVIDADE E INOVAÇÃO NAS MICROCERVEJARIAS DO NOROESTE DO RIO GRANDE DO SUL
} Competitiveness and Innovation in Micro Brewers in the Northwest of Rio Grande do Sul

\author{
André Rodrigo BRAGANHOLO \\ Departamento de Economia, \\ Universidade Federal da Fronteira Sul - UFFS, \\ Brasil \\ andre_braga@hotmail.com \\ Ricardo Aguirre de MORAES \\ Departamento de História, Departamento de \\ Economia, \\ Universidade Federal de Santa Marina - UFSM, \\ Brasil \\ aguirredemoraes@hotmail.com
}

\author{
Fabiano GEREMIA \\ Departamento de Administração, \\ Universidade Federal da Fronteira Sul - UFFS, Brasil \\ fageremia@gmail.com \\ Thales de Oliveira Costa VIEGAS \\ Departamento de Economia \\ Universidade Federal de Santa Marina - UFSM, Brasil \\ thales.viegas@ufsm.br \\ Leandro Gabriel FLAMINO \\ Departamento de Economia, \\ Universidade Federal de Santa Marina - UFSM, Brasil \\ flamino.leo@gmail.com
}

\section{RESUMO}

Objetivo: Este trabalho analisa as características competitivas das microcervejarias artesanais da região Noroeste do estado do Rio Grande do Sul. As cervejas artesanais têm ganhado espaço na preferência dos consumidores, uma vez que uma cerveja artesanal apresenta uma fórmula de produção ímpar, bem como aromas e sabores diferenciados, o que atrai novos consumidores. Neste artigo são analisadas as especificidades competitivas das empresas, as características da estrutura produtiva, os processos de aprendizagem, as vantagens de localização e a estrutura institucional de apoio. Com base na literatura sobre a dinâmica inovativa do referencial Neo-schumpeteriano, foi realizada uma pesquisa de campo, com questionário estruturado para fundamentar a análise das características e capacitações tecnológicas das empresas. Os resultados obtidos apontam que a qualidade da matéria-prima e as inovações nos produtos e nos processos produtivos são extremamente relevantes para a sobrevivência das empresas nesse nicho de mercado, já que a concorrência não se manifesta via preços, mas por meio da diferenciação (qualidade) dos produtos. Conclui-se que o processo de gourmetização, que transformou o comportamento dos consumidores, criou um novo mercado, que se constitui na principal justificativa para a existência de microcervejarias na região Noroeste. Outros fatores competitivos locais não foram considerados relevantes pelas empresas.

PALAVRAS-CHAVE: Microcervejarias. Processos de aprendizado. Competitividade.

\begin{abstract}
Objetive: This article analyzes the features of microbrewery from the northwestern region of Rio Grande do Sul. Handcrafted beers have won the preference of many consumers, because its production formula is unique and the aromas and flavors are differentiated, which attracts new consumers. This paper discusses the competitive specificities of the companies, the features of the productive structure, the learning processes, the location advantages and the institutional structure that support the companies. Based on the literature on the innovative dynamics of the Neo-Schumpeterian, a survey was conducted with a structured questionnaire to support the analysis of the features and technological capabilities of the companies. The results show that the quality of the raw material, the innovations in the products and in the productive processes are extremely relevant for the survival of the companies in this market niche, since the competition is not manifested through prices, but through the differentiation (quality) of product. We concluded that the gourmetization process, that changed the behavior of the consumers, created a new market, which constitutes the main justification for the existence of microbreweries in the Northwest region. Other local competitive factors were not considered relevant by companies.
\end{abstract}

KEYWORDS: Microbrewery. Learning Process. Competitiveness.

Classificação JEL: L26; L66

Recebido em: 24-04-2019. Aceito em: 14-08-2019. 


\section{INTRODUÇÃO}

O mercado de cerveja é um importante gerador de emprego e renda em diversas partes do mundo. No Brasil, a produção de cerveja era inicialmente para consumo familiar e rapidamente tornou-se um produto comercial, que ganhou grandes proporções com aberturas de grandes empresas cervejeiras, que se tornaram líderes de mercado (CERVESIA, 2014). Logo ocorreram expansões de firmas estabelecidas, associações e aberturas de mais empresas, que ganharam lugar de destaque na economia brasileira, com a geração de emprego e renda.

Neste contexto, as cervejas artesanais e o chopp fabricado por microcervejarias são tipos de produto que têm sido cada vez mais apreciados pelos consumidores, de modo que nas últimas décadas ambos ocuparam maior espaço no mercado. Contudo, pode-se afirmar que o mercado para microcervejarias ainda é incipiente e busca superar o consumo destinado a eventos sazonais e/ou apenas por consumidores de classe média ou alta.

Diante deste contexto, o presente estudo analisa os fatores determinantes da competitividade, da inovação e dos processos de aprendizagem em microcervejarias da região Noroeste do estado do Rio Grande do Sul. Apesar de se encontrar distante dos grandes centros consumidores, a região em estudo possui diversas microcervejarias recentemente criadas. Isso pode indicar que esteja em curso uma mudança no comportamento dos consumidores, bem como nos fatores competitivos que envolvem esse segmento de atividade. Nesse contexto, este estudo procura entender as principais características produtivas e os elementos considerados essenciais para a inserção competitiva no mercado consumidor de empresas neste segmento de atividade.

Este artigo encontra-se dividido em seis seções além desta introdução. Na próxima seção são apresentados os aspectos teóricos e conceituais sobre a competitividade, aprendizagem e inovação que servem de base para análise dos resultados. Na terceira seção são destacadas as principais características do sistema produtivo e inovativo do segmento cervejeiro, com destaque para as microcervejarias artesanais. Enquanto que na seção quatro é analisada a importância dos novos hábitos de consumo no mercado de cervejas artesanais. Na seção cinco são apresentados os procedimentos metodológicos adotados para a realização da pesquisa. Já na seção seis são analisados os principais resultados da pesquisa de campo nas microcervejarias artesanais da região noroeste do 
estado do Rio Grande do Sul. Na última seção, são condensadas as principais conclusões do estudo.

\section{ASPECTOS CONCEITUAIS DA COMPETITIVIDADE, APRENDIZAGEM E INOVAÇÃO}

O referencial teórico adotado nesta pesquisa foi o Neo-schumpeteriano, que destaca o processo de transformação do sistema capitalista como resultado do esforço inovativo das firmas. Na concepção Neo-schumpeteriana, o desenvolvimento econômico está associado ao desenvolvimento e implementação de novas tecnologias.

A teoria Neo-schumpeteriana trata o desenvolvimento capitalista através de um processo evolutivo, em que as firmas aprendem a partir do método de tentativa e erro. Mckelvey, Zaring e Szucs (2015) aponta que os autores evolucionistas defendem também a ideia de que a empresa é capaz de se aperfeiçoar constantemente através de métodos de aprendizagem, em que a interação com tecnologias permite os chamados "upgrade's" das firmas em seus processos tecnológicos, convertidos em determinado bem ou serviço.

Para Schumpeter (1988), o processo inovativo pode ser dividido em três estágios: a) Invenção, caracterizada pela criação de um novo produto, novo processo ou novo serviço, mas que ainda não apresenta finalidade comercial; b) imitação ou difusão, caracterizada pela existência de empresas seguidoras, e; c) inovação, que desempenha o papel de suprir a demanda por novos produtos, novos processes ou novos serviços. Ainda de acordo com o autor, existe uma importante diferença econômica entre o processo inovativo e a simples invenção. De acordo com Rita et al (2017) a invenção nada mais é que uma ideia, molde ou projeto de um novo produto, processo ou sistema, enquanto que a inovação se materializa na medida em que aquela invenção se torna comercial, ou seja, é introduzida no mercado e gera riqueza para quem a produz e a comercializa.

De acordo com Lundvall (1988); Schwartz e Bar-el (2015), o processo de inovação pode ser dividido em três tipos, a saber: incremental, radical e as revoluções tecnológicas. As inovações incrementais podem ser definidas como pequenos melhoramentos em produtos ou em processos produtivos. Enquanto as radicais caracterizam-se como inovações que transformam os mercados ou mesmo o sistema produtivo, a partir delas as inovações incrementais são desenvolvidas. Por fim as inovações ocasionadas pelas 
revoluções tecnológicas definem as novas trajetórias de desenvolvimento das tecnologias, em especial por inalgurarem um novo padrão de acumulução produtiva.

Enquanto que Bell e Pavitt (1993) distinguem as inovações entre investimentos tangíveis e investiementos intangíveis. Os primeiros estão mais relacionados ativos físicos, como à aquisição e/ou modernização de máquinas e equipemantos, enquanto que os investimentos intangíveis estão ligados ao desenvolvimento de capacitações e habilidades técnicas da empresa, em especial a qualificação da mão de obra.

Segundo Simantob e Lippi (2003), no sistema econômico capitalista, uma empresa ou setor que pretenda ser exitosa em seu ramo de atividade, necessita de conhecimentos voltados para o seu aperfeiçoamento constante, que possibilitam o surgimento de novos produtos, novos processos e novos mercados. Em micro e pequenas empresas as dificuldades para a realização de inovações tecnológicas são ainda maiores. Neste sentido, a cooperação entre os agentes produtivos pode se caracterizar em uma alternativa importante para a dinamização de inovações. Conforme destaca Carvalho et al (2016), a base para a cooperação é a confiança, já que os agentes precisam acreditar que não serão prejudicados pelos concorrentes no ambiente competitivo.

A inovação é a concretização de ideias criativas que buscam solucionar algum gargalo (problema) identificado e/ou o aprimoramento de produtos e de processos organizacionais. A inovação pode engendrar algo simples ou algum elemento extremamente revolucionário. É preciso que a inovação envolva alguma novidade e produza resultados positivos, isto é, deve produzir benefícios econômico-financeiros.

Freeman e Soete (2008) salientam que compreender as inovações auxilia o entendimento das transformações no mercado e todos os agentes que podem influenciálo. Para os empreendedores, definir o tipo de inovação que está sendo feito ajuda a entender os seguintes elementos: a) quais serão as necessidades da empresa; b) como ingressar no mercado e; c) como assumir posições competitivas capazes de criar algum poder de mercado.

O aprendizado envolve os mecanismos de produção e transmissão de conhecimento e constitui-se em um fator necessário para a busca da solução de problemas. Malerba (1992) e Malerba et al (2015) destacam que existem diversas formas de aprendizado, cada uma com seu grau de importância para o sucesso e a criação de conhecimento, com destaque para os seguintes tipos: a) aprender fazendo (learning by doing); b) Aprender usando (learning by using); c) Aprender pesquisando (learning by searching); d) Aprender com os avanços em ciência e tecnologia (learning from advances in science and 
technology); e) Aprender com os excedentes inter-indústrias (learning from inter-industry spillovers), e; f) Aprender com interações (learning by interacting).

A utilização do método de tentativa e erro é um modelo altamente utilizado pelas empresas e seus resultados estão condicionados à combinação adequada com as formas de aprendizado utilizadas. Diante do mecanismo schumpeteriano da destruição criadora (SCHUMPETER, 1988), as empresas "lutam" contra a obsolescência, a partir da combinação de aprendizagem e inovação, que são essenciais para as organizações se adaptarem às constantes mudanças do mercado.

Em termos tecnológicos, o esforço individual das firmas pode não apresentar grandes diferenças entre as nações, já que as diferenças podem estar mais relacionadas ao macroambiente. $\mathrm{O}$ ambiente externo - as firmas, com infraestrutura de financiamento, abrangência em atividades com elevado grau de incertezas, educação básica, científica e tecnológica - pode ser responsável pelo sucesso comercial de esforços realizados pelas firmas na transformação do sistema capitalista, através da introdução de inovações.

\section{SISTEMA PRODUTIVO E INOVATIVO CERVEJEIRO}

A cerveja é a bebida alcoólica mais conhecida do mundo, contudo os países que mais a consomem, não são os principais produtores. Neste quesito, o Brasil pode ser considerado um caso sui generis, uma vez que está entre os maiores produtores e também entre os maiores consumidores mundiais. A produção do Brasil é superior à de países como a Rússia e Alemanha que estão em quarto e quinto lugar, respectivamente. Ela é inferior apenas à produção da China (maior produtor) e dos Estados Unidos (segundo maior fabricante) (SEBRAE, 2015).

Segundo Morado (2009), até o começo dos anos 2000, o mercado brasileiro de cervejas apresentava pouca diversidade de ofertas de estilos, concebia-se a ideia que as cervejas eram todas iguais. Neste contexto, a produção era basicamente direcionada para consumidores de menor poder aquisitivo. O comportamento requintado se verificava no consumo de vinhos, com suas diferenciações de tipos, safras e preços, o que constituía uma distinção social entre os adeptos do consumo de vinho vis a vis o de cerveja. A cerveja era vista como uma bebida da massa, que liderava o mercado de bebidas alcoólicas do país, enquanto o vinho, reduzido a uma pequena fatia do mercado, apresentava opções para a escolha dos seus consumidores. 
As microcervejarias artesanais apresentam características particulares que as diferenciam das grandes cervejarias. De acordo com a AFEBRAS (2013), as grandes cervejarias deste sistema produtivo empregam, em média, apenas dois empregados para cada um milhão de litros produzidos de cerveja, enquanto as microcervejarias e cervejarias de pequeno porte empregam aproximadamente trinta funcionários para os mesmos um milhão de litros produzidos.

De acordo com a CERVBRASIL (2016), o sistema produtivo cervejeiro emprega direta e indiretamente cerca de 2,2 milhões de trabalhadores. Essa cadeia produtiva compreende desde agricultores que cultivam a matéria-prima para a produção, os importadores, as fábricas que processam os insumos, os fabricantes de garrafas, latas, tampinhas, embalagens, rótulos e equipamentos, bem como as redes de logística, distribuição e comercialização do produto, contemplando até a linha de acessórios e equipamentos para degustação e produção caseira da bebida.

Ainda de acordo com a CERVBRASIL (2016), esse sistema é um importante gerador de renda, uma vez que são pagos, apenas na forma de salários, cerca de $R \$ 27$ bilhões. $O$ sistema produtivo cervejeiro brasileiro apresentou em 2015 um faturamento superior aos $\mathrm{R} \$ 70$ bilhões. A partir destes dados estima-se que esse segmento de atividade contribua para a geração de impostos em, aproximadamente, $R \$ 21$ bilhões anuais, demonstrando que a indústria da cerveja brasileira contribui para o desenvolvimento econômico e social do país. O crescimento desde sistema produtivo no período recente é explicado, em parte, pela mudança nos padrões de demanda e consumo de cerveja, conforme destacado na próxima seção.

\section{NOVOS HÁBITOS DE CONSUMO E O MERCADO DAS CERVEJAS ARTESANAIS}

As microcervejarias não são concorrentes diretas das cervejarias industriais, uma vez que os seus custos unitários de produção são mais altos, o que justifica o fato de as primeiras não tentarem competir em preços com as últimas. Embora a grande empresa oligopolista seja tecnicamente mais avançada e inovadora do que a pequena empresa, as fábricas industriais são mais influenciadas pelas microcervejarias do que o contrário, pelo menos em termos de inovação de produto. Isso ocorre porque estas são mais livres para experimentar e os consumidores de microcervejarias são muito mais propensos a ignorar 
as imperfeições sensoriais em seus produtos do que os consumidores das cervejarias industriais (MAIER, 2013). Neste contexto, segundo Limberger e Tulla (2017), a fabricação de cervejas especiais, de alto valor agregado, passou a ser interessante para a grande indústria, o que levou muitas cervejarias a adquirir microcervejarias artesanais ao redor do mundo.

O diferencial das microcervejarias se manifesta na qualidade sensorial que é devida aos ingredientes de alta qualidade utilizados. As concorrentes diretas das microcervejarias brasileiras são as cervejas artesanais importadas, que custam ainda mais caro que as nacionais. Este fato contribuiu para o sucesso dos produtores locais. De acordo com Stefenon (2012), o surgimento de um novo padrão de consumo brasileiro de cervejas tem condicionado as grandes cervejarias a se reinventarem no processo produtivo cervejeiro. Neste contexto, o fenômeno das cervejas especiais forçado as grandes cervejarias a: i) desenvolver produtos focados para este segmento; ii) aquisição de pequenas cervejarias especializadas em cervejas especiais (microcervejarias) e; iii) expansão da oferta de marcas importadas. Neste contexto, as cervejas premium ou gourmet apresentam características especiais que denotam qualidade superior, por serem produzidas com matérias-primas nobres e processos de fabricação mais refinados quando comparadas às cervejas produzidas em grande escala.

Neste contexto, identifica-se um processo de "construção" de uma cultura específica, o mercado de cerveja artesanal. Tendo em vista que este produto ainda é demandado por uma parcela reduzida da população brasileira, os termos "tradição" e "cultura" são oportunos na medida em que contribuem para instigar o consumo de cerveja artesanal (GOIA e CHAVES, 2017). Esse fenômeno corresponde ao conceito de "tradição inventada" de Hobsbawm (2013), na medida em que se manifestou a "fabricação da cultura da cerveja artesanal". Segundo este autor, as tradições inventadas conformam um conjunto de práticas, orientadas por regras explícitas ou tácitas aceitas, que se reproduzem na forma de rituais que condicionam comportamentos por repetição e sugerem um culto a costumes passados, tradicionais.

Segundo Lages (2016), o circuito gourmet preza pela complexidade do prazer gastronômico. Em certo sentido, propõe um retorno à lógica europeia (francesa, em particular) que elevou a culinária ao status de arte e o ato de se alimentar a partir da degustação de sabores requintados. Neste sentido, a reorganização do mercado gourmet promove novos símbolos e novos rituais de consumo, que estão associados a padrões superiores de experiência sensorial. 
A difusão do consumo da cerveja artesanal está associada, primeiramente, ao processo de "gourmetização" geral dos bens verificada no Brasil no período recente. Esse fenômeno expressa a busca pela distinção social de parte crescente da população. Em segundo lugar, a efervescência da cerveja artesanal reflete a exaltação do que se convencionou chamar de "cultura da cerveja". Adicionalmente, o atual movimento cervejeiro apresenta múltiplas facetas, uma vez que a "cultura cervejeira" está sustentada por dois fundamentos aparentemente antagônicos. O primeiro é de natureza conservadora, pois remonta comportamentos tradicionais que envolvem padrões de qualidade e consumo passados, manifestos no produto artesanal. Está conectado à ressignificação da comida artesanal/rústica, que vem sendo valorizada por se aproximar da "alta gastronomia" e daquilo que é pregado pelo Slow Food (movimento crítico à comida industrializada). Há que se salientar que a cerveja é um alimento complexo em termos organolépticos. Já o segundo aspecto é transformador ao propor a substituição do hábito de demandar cervejas populares, produzidas em larga escala, como forma de resistência à massificação da cerveja e ao monopólio da produção mantido por grandes corporações (GIORGI, 2017).

De acordo com Maier (2016), um fato paradoxal se manifestou no aumento do consumo de cervejas artesanais durante a crise econômica global, momento em que aumentou o número de microcervejarias ao mesmo tempo em que o consumo geral de cerveja na República Tcheca caiu. Um fato semelhante teria acontecido no Brasil nos últimos dois anos. Segundo Regis, Pereira e Salazar (2017), nos últimos anos, caracterizados por recessão econômica, enquanto a produção nacional de cervejas das grandes empresas caiu cerca de $2,0 \%$, as cervejas especiais tiveram um crescimento de vendas e de consumo vertiginoso, da ordem de $36 \%$. Na próxima seção serão apresentados os principais procedimentos metodológicos utilizados no estudo.

\section{METODOLOGIA}

O presente estudo tem caráter exploratório, com a realização de entrevistas às empresas microcervejarias da região Noroeste do estado do Rio Grande do Sul de forma censitária. O questionário utilizado nas entrevistas foi estruturado de maneira que as empresas estabeleciam um grau de importância, grau de dificuldade ou grau de conhecimento para cada alternativa apresentada no questionário. As questões foram 
adaptadas a partir do questionário ${ }^{1}$ da Rede de Pesquisa em Sistemas e Arranjos Produtivos e Inovativos Locais (REDESIST, 2003) - do Instituto de Economia da Universidade Federal do Rio de Janeiro.

O objetivo central das questões aplicadas foi a identificação dos fatores determinantes da competitividade das microcervejarias e cervejas artesanais. As entrevistas identificaram: a) o esforço para introdução de inovações tecnológicas; b) as dificuldades para contratar empregados qualificados; c) as dificuldades para vender a produção; d) os fatores determinantes da capacidade competitiva; e) a importância das atividades de capacitação de recursos humanos; f) as dificuldades de produzir com qualidade; g) as dificuldades relacionadas aos custos ou falta de capital de giro; h) a importância dos custos de aquisição de máquinas e equipamentos; i) a importância do acesso à matéria prima; j) as vantagens locais, e; k) as fontes de informações utilizadas pelas empresas.

As entrevistas foram realizadas entre os meses de abril até junho do ano de 2016, junto aos seus proprietários e/ou gerentes. As entrevistas realizadas diretamente com os principais responsáveis pelas empresas serviram para buscar melhor entendimento da produção, da competitividade e do esforço inovativo realizado pelas microcervejarias. $\mathrm{O}$ questionário foi adaptado com o intuito geral de que o entrevistado respondesse o grau de importância ou dificuldade atribuindo um valor entre 0 e 3.

Em posse de todas as entrevistas realizadas, foi produzida uma média ponderada com base nas respostas das firmas entrevistadas. Estas empresas não serão identificadas neste trabalho, uma vez que as informações prestadas são estratégicas para essas organizações.

\section{CARACTERÍSTICAS DO SISTEMA PRODUTIVO E INOVATIVO DAS MICROCERVEJARIAS ESTUDADAS}

A partir das informações geradas através do acesso à Relação Anual de Informações Sociais (RAIS), foram identificadas sete (07) microcervejarias artesanais na região Noroeste do estado do Rio Grande do Sul (RAIS, 2016), as quais foram contatadas e entrevistadas, foram pesquisados todas as microcervejarias que se classificaram com 0

\footnotetext{
${ }_{1}^{1}$ Disponível na página: www.redesist.ie.ufrj.br
} 
CNAE - 11.13-5 (Classificação Nacional de Atividades Econômicas). A capacidade produtiva das empresas estudadas varia entre 2.000 litros/mês até 180.000 litros/mês, contudo todas as firmas são classificadas como microempresas ${ }^{2}$ e apresentam períodos de existência relativamente curtos, que variam entre três e dez anos. Os sócios proprietários ou fundadores possuem conhecimentos tácitos, adquiridos com experiências em outros segmentos de atividade econômica.

A necessidade de realizar constantes investimentos em novas tecnologias justificase pela forte concorrência enfrentada pelas microcervejarias artesanais, capitaneadas pelas grandes empresas que compõem este sistema produtivo. Assim, a inovação é estratégica no processo produtivo, na definição de aromas e sabores, bem como para a introdução e manutenção de determinada marca no mercado.

$\mathrm{Na}$ Figura 1 são apresentados aspectos que podem representar desafios para as empresas, que são expressos na forma de "grau de dificuldade" para as microcervejarias da região Noroeste. Os questionamentos se referem a circunstâncias correlatas ao ano de criação da empresa e ao ano de realização da pesquisa.

\footnotetext{
${ }^{2} \mathrm{O}$ porte das empresas foi definido a partir do número de empregados. As micro são empresas que possuem até 20 empregados, pequenas empresas de 21 à 99 empregados, médias empresas de 100 a 499 empregados e grandes empresas acima de 500 empregados.
} 
Figura 1 - Grau de dificuldade ${ }^{3}$ atribuído pelas microcervejarias da região Noroeste do estado do Rio Grande do Sul - RS, no ano de criação e no ano em que foi realizada a entrevista 2016

ఐ No ano de 2016 No ano de criação da empresa

Contratar empregados qualificados

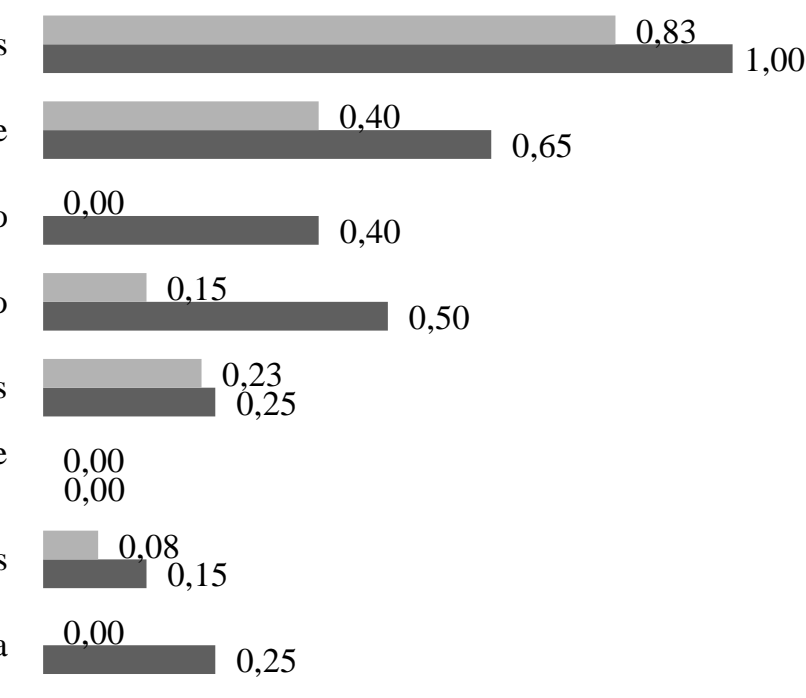

Custo ou falta de capital para aquisição de máquinas

Custo ou falta de capital para aquisição de instalações

Pagamento de emprestímos

Importação de matéria-prima

Produzir com qualidade

Vender a produção

Custo ou falta de capital de giro .$$
\text { (1) }
$$

Fonte: Pesquisa de campo (2016)

Segundo os entrevistados, devido ao pleno conhecimento de todas as etapas da fabricação da cerveja, o grau de dificuldade para "Produzir com Qualidade" não demonstrou ser tão alto quando comparado ao desafio de "Contratar Empregados Qualificados". Contudo, uma dificuldade identificada como significativa refere-se à organização inicial do layout da área de produção, bem como a aquisição de familiaridade (e competência prática) no manejo dos equipamentos de produção. Nos primeiros meses de existência das firmas os consumidores apresentam receio de adquirir e consumir cervejas novas, mas com o passar do tempo a dificuldade de vender a produção deixou de ser relevante, tendo em vista que os empresários adaptaram receitas em relação às preferências dos consumidores locais.

Os equipamentos de produção são planejados, especialmente, para esta atividade econômica, podendo ser projetados e encomendados pelo mestre cervejeiro, a seu gosto, de modo que eles dependem apenas da estrutura física do local da produção, que pode

\footnotetext{
${ }^{3}$ Os índices foram atribuídos através da média ponderada das respostas obtidas nas entrevistas às empresas estudadas. Estas, ao responder o questionário, atribuíram um grau de importância para cada item. O grau de importância poderia ser nulo, baixo, médio ou alto. A ponderação foi feita da seguinte forma: " $0 * \mathrm{~N}^{0}$ nula $+0,30^{*} \mathrm{~N}^{0}$ baixa $+0,6^{*} \mathrm{~N}^{0}$ média $+\mathrm{N}^{0}$ Altas $/ \mathrm{N}^{\circ}$ de empresas que respondeu o questionário. A média varia entre 0 e 1 , onde 0 é considerado nulo e gradativamente até 1 com importância máxima.
} 
apresentar limitações de espaço. Este aspecto foi verificado em todas as empresas entrevistadas, uma vez que a maioria adquiriu, com recursos próprios, as instalações e estruturas físicas. Entretanto, algumas empresas necessitaram de recursos de terceiros para a aquisição de máquinas e equipamentos. Cumpre notar que as firmas apresentaram alguma dificuldade na obtenção de capital de giro no ano de criação, mas esse fato foi amplamente superado com o desenvolvimento da atividade. Não foram identificadas grandes dificuldades pelos empresários para adesão aos modelos de financiamentos existentes nesse segmento de atividade.

Em comparação com o primeiro ano de funcionamento da empresa, no ano de 2016 foi constatado que algumas dificuldades iniciais já não se fazem mais presentes no cotidiano das empresas. Por exemplo, para vender a produção não se reconhece mais dificuldades, já que a partir do estabelecimento de parcerias com bares e restaurantes, constitui-se algum grau de fidelidade de consumo relativa ao produto ofertado, de modo que se torna mais "fácil" comercializar a produção. No tocante à importação de matéria prima, a dificuldade se tornou nula, tendo em vista que depois da criação do vínculo entre a empresa e a distribuidora, o processo de negociação se torna bastante simples.

No quesito relativo à situação financeira, como capital de giro e aquisições de instalações, foram encontradas dificuldades apenas no início da atuação das empresas. Isso ocorreu porque algumas delas necessitaram de financiamentos para a abertura da empresa, mas a partir do próprio fluxo de caixa gerado pelo empreendimento os financiamentos contraídos foram facilmente quitados. Isso permitiu que a maioria dos empresários entrevistados quitasse os valores financiados antes mesmo do prazo contratado. A partir disso abriu-se caminho para expansões significativas, principalmente na capacidade produtiva.

A Figura 2 demonstra o índice de importância atribuído pelas empresas aos fatores que determinam a manutenção da sua capacidade competitiva na principal linha de produtos. Estes, segundo as empresas, estão intimamente relacionados à qualidade do produto, o que depende da qualidade técnica da mão de obra utilizada. Estes pontos foram muito salientados pelos entrevistados, uma vez que todos afirmam que o esforço de produzir com qualidade máxima e diferenciação frente às empresas concorrentes é o objetivo fundamental de cada organização. 
Figura 2 - Grau de importância ${ }^{4}$ dos fatores determinantes para manter a capacidade competitiva na principal linha de produto das microcervejarias da Região Noroeste do estado do Rio Grande do Sul - RS

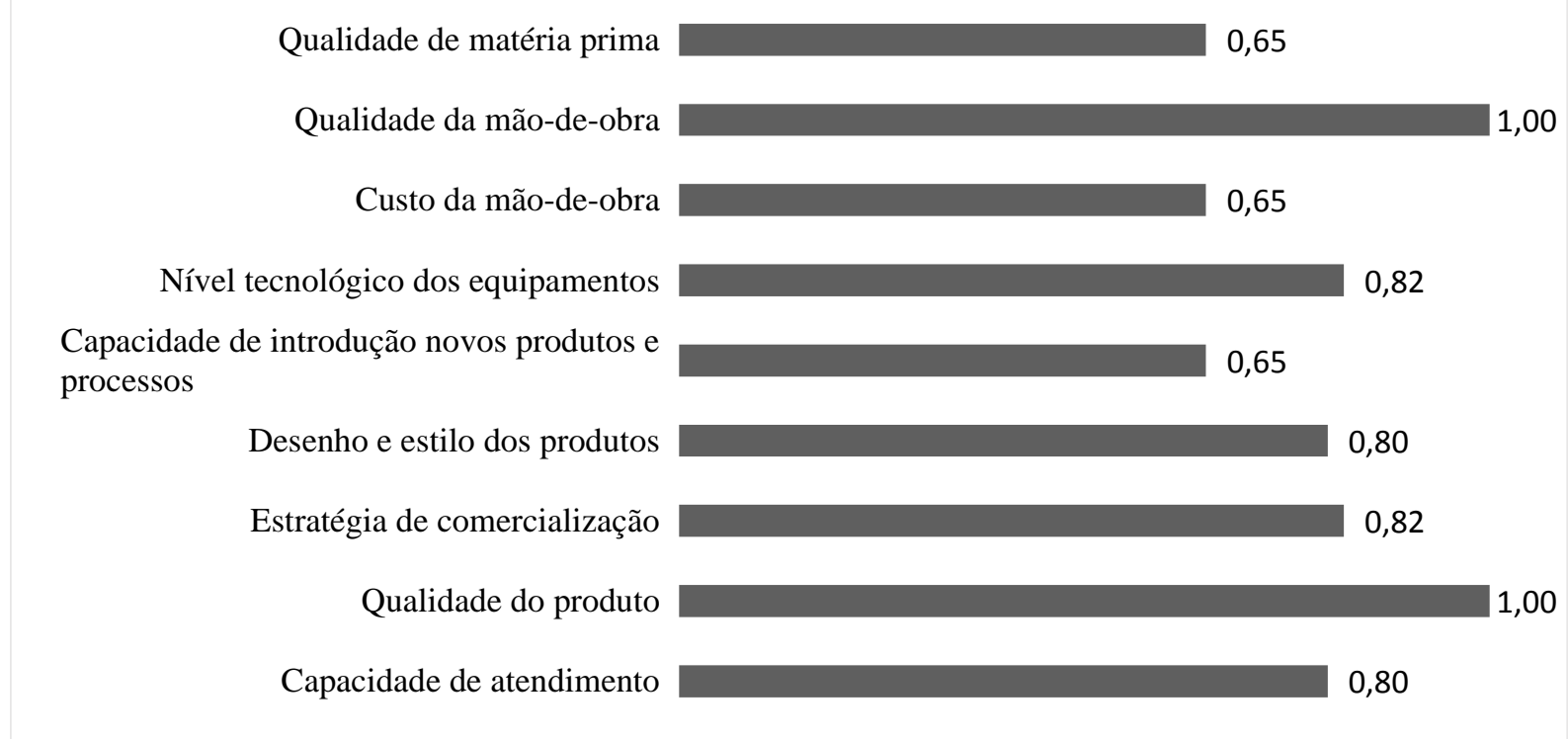

Fonte: Pesquisa de campo (2016)

Percebeu-se, a partir das entrevistas realizadas, que os concorrentes exercem pressões competitivas importantes para que as empresas sigam promovendo inovações e melhorando sua principal linha de produtos. Neste nicho de mercado a concorrência não ocorre via preço, mas predominantemente através da diferenciação de produtos, baseada na agregação de valor aos bens e aos serviços vendidos. Tal diferenciação desperta um maior interesse dos clientes e consumidores. Os riscos inerentes a essas diferenciações são simplesmente ignorados pelas empresas, já que isso pode ser embutido no preço final do produto.

Ainda de acordo com o demonstrado na Figura 2, percebe-se que todos os indicadores apresentam um grau de importância considerável. Contudo, os entrevistados destacaram que os determinantes da produção eficiente e de qualidade são constituídos pela capacidade de atendimento ao cliente e pelo nível tecnológico do equipamento de fabricação do produto. Nestes quesitos, os entrevistados destacam que os clientes costumam desenvolver fidelidade nas relações comerciais, mas uma vez decepcionadas

\footnotetext{
${ }^{4}$ Grau de importância $=$ (Número de nulas * $0+$ Número de baixa * $0,30+$ Número de média * 0,60 + Número de alta) / Número de empresas pesquisadas.
} 
não costumam voltar a demandar os produtos. Em função disso, é muito importante manter a relação de confiança entre produtor e clientes.

Os fatores estratégicos para comercialização estão associados à capacidade de introduzir novos produtos ou processos na empresa, bem como à capacidade de elaborar desenhos e estilos de produtos em si, mas também de rótulos, embalagens e afins. Esses elementos as tornam mais aptas a se firmar cada vez mais no mercado. Por fim, a qualidade da matéria prima é o que garante, em última instância, o grau de inserção no mercado consumidor, por isso, com frequência, as empresas devem utilizar insumos com custo relativamente alto para não diminuir o grau de satisfação de consumidores e clientes.

A constância do esforço inovativo identificada nas entrevistas demonstra que as cervejarias da região têm empreendido recursos significativos para se manterem no mercado. Neste quesito, a aquisição de equipamentos e maquinários com nível tecnológico superior aos que eles já possuíam, com sistemas mais automatizados e atualizados apresentou o maior índice de importância. Essas aquisições são relevantes para a realização de inovações de processos, produtos e serviços, pois com novos equipamentos é possível otimizar a produção, como também facilitar o manuseio e os processos de fabricação.

O esforço inovativo, embora ocasionalmente, também se concentrou na busca de novas formas de comercialização e distribuição, modernizações organizacionais, treinamentos direcionados a introdução de novos produtos e na introdução de projetos ou desenhos industriais. Conforme destacado pelos entrevistados, a relevância que estas inovações têm para as empresas e a lucratividade obtida é de média importância, já que as inovações introduzidas não implicam em ganhos significativos, mas são necessárias para manter-se na fronteira tecnológica da produção cervejeira.

O resultado e os impactos das inovações introduzidas durante os dois anos anteriores às entrevistas foram identificados como significativos. Os indicadores de maior importância foram o aumento de produtividade proporcionado pelas inovações introduzidas no período. Essas estão intimamente relacionadas à inclusão de atividades e processos inovativos, principalmente com a aquisição de equipamentos com maior capacidade e com um nível de automação mais atualizado. Isso permitiu que a empresa se mantivesse competitiva no mercado em que atua como também promoveu o aumento da qualidade e da gama de produtos ofertados, juntamente com o aumento de participação no mercado. Outro efeito, vinculado ao aumento de produtividade da empresa, se encontra no estabelecimento de parcerias com empresas ligadas à logística de distribuição. Neste 
sentido, alguns criam pontos de venda e entrega diretamente para o consumidor final, permitindo maior inserção no mercado consumidor.

O esforço inovativo empreendido não possibilitou a redução dos custos de matéria prima, uma vez que os seus preços estão associados ao mercado externo. Ademais, para cada receita elaborada e preparada é necessário um valor " $x$ " de insumos, não dependendo da qualidade e nível tecnológico instalado na empresa, e sim diretamente dos insumos necessários. Porém, devido às inovações introduzidas na empresa, foi possível reduzir principalmente os impactos que eram gerados ao meio ambiente de diversas formas, tais como: a) aquisições de equipamentos para a purificação da água de lavagem dos tanques de fermentação e os utensílios em geral que antes eram desperdiçados e, após implementação, puderam ser reutilizados; b) redução na energia consumida para a fabricação devido à aquisição de tanques maiores para fermentação, os quais conseguem armazenar volumes de cerveja muito superiores aos iniciais, com significativa redução do consumo de energia.

As atividades de treinamento e capacitação de recursos humanos realizados pelas cervejarias pesquisadas podem ser observadas na Figura 3. Os recursos humanos são essenciais para a realização de produção com nível de qualidade aceitável pelo mercado consumidor. Esse fato é reconhecido pelos entrevistados, os quais afirmaram que o nível tecnológico dos equipamentos não compensa eventuais deficiências na formação dos recursos humanos da empresa.

O nível de importância atribuído ao treinamento e à capacitação, por intermédio de cursos técnicos dentro do setor cervejeiro, é considerado indispensável, pois é através desta interação que se agregam conhecimentos empíricos, os quais são imprescindíveis para o aumento da qualidade do produto.

Conforme pode ser observado na Figura 3, outras formas de treinamento e capacitação de recursos humanos não são consideradas relevantes pelas empresas. Essa percepção pode ser traduzida pelo baixo tempo de atuação neste mercado, uma vez que empresas com pouco tempo de criação tendem a se concentrar em questões mais gerais de operacionalização da produção e se preocupam menos com o treinamento da mão de obra em nível interno da firma.

As formas de aprendizado são uma importante maneira de identificar o esforço inovativo das firmas, já que o desenvolvimento tecnológico ocorre a partir da acumulação de conhecimentos que as firmas adquirem ao longo de sua trajetória. A Figura 4 destaca a importância atribuída pelas empresas em relação às principais formas de aprendizado. As 
principais formas de aprendizado identificadas advêm de fontes internas, como resultado de experimentos na área de produção, o chamado "learning by doing", e na área de vendas como resultados de feedback dos clientes, com os chamados "learning by using". Esse aspecto sugere que o aprendizado é basicamente informal, resultado do baixo nível técnico da mão de obra local, da constituição recente das empresas e da baixa importância atribuída pelas empresas pesquisadas à absorção de formando dos cursos universitários.

Figura 3 - Grau de Importância ${ }^{5}$ das atividades de treinamento e capacitação dos recursos humanos durante os últimos anos (2014 a 2016), efetuadas pelas empresas microcervejarias da região Noroeste do estado do Rio Grande do Sul - RS

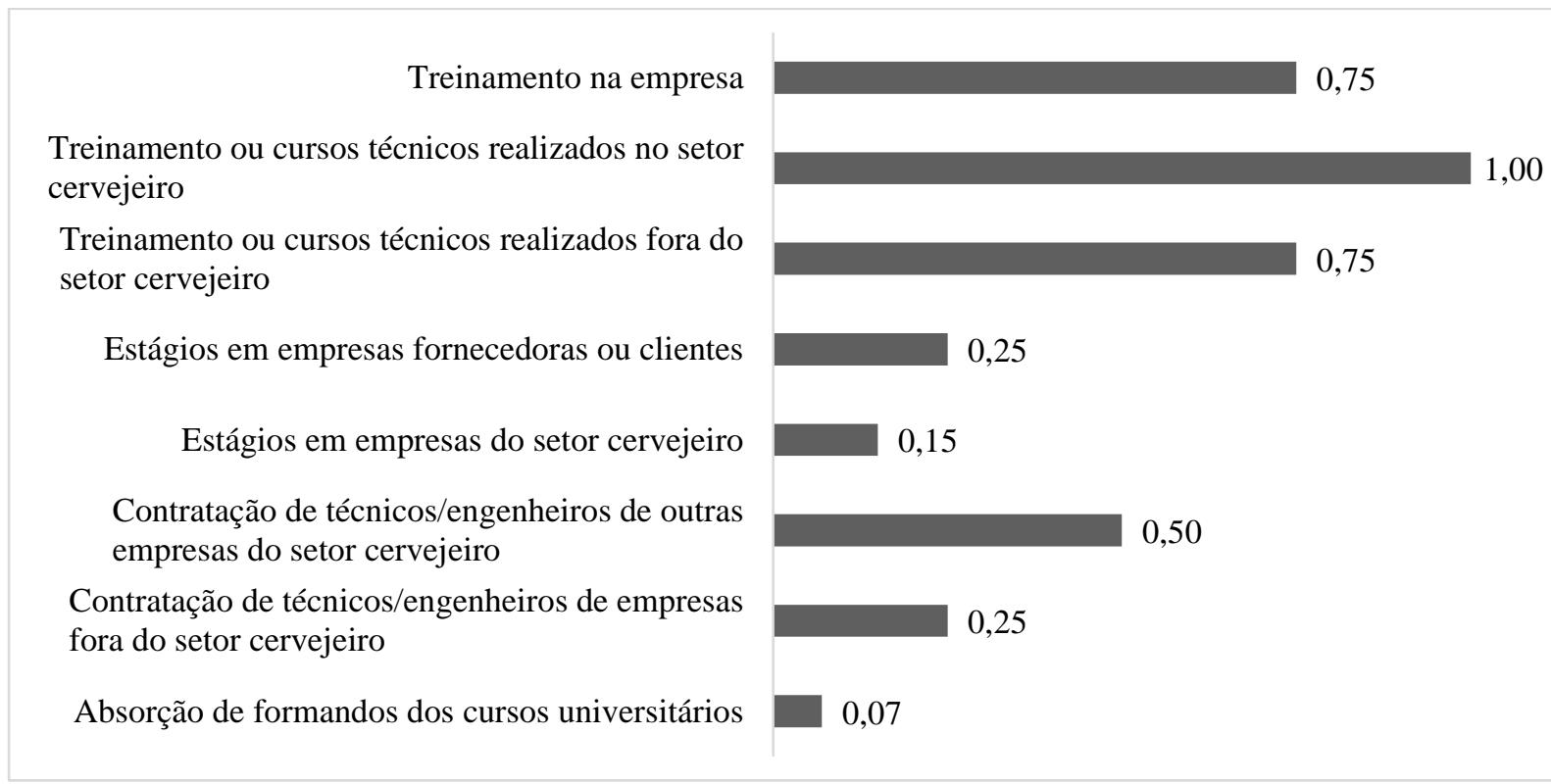

Fonte: Pesquisa de campo (2016)

Os conhecimentos advindos de pesquisas científicas em universidades, centros de capacitação profissional, institutos de testes, ensaios e certificações possuem baixa importância para as empresas cervejeiras da região Noroeste do estado do Rio Grande do Sul. Esse fato deve-se a baixa importância atribuído aos investimentos em P\&D, bem como a relativa incipiência desta indústria na região, uma vez que empresas recém-criadas estão mais preocupadas em se estabelecer no mercado do que desenvolver relações com instituições científicas. Por outro lado, deve-se também à baixa existência e/ou inexistência de institutos de pesquisas especializados em desenvolver esse segmento de atividades na região estudada.

${ }^{5}$ Grau de importância $=$ (Número de nulas * $0+$ Número de baixa * $0,30+$ Número de média * 0,60 + Número de alta) / Número de empresas pesquisadas. 
As empresas investigadas utilizam-se de feiras, exibições e seminários, conferências e cursos relacionadas a esse segmento de atividade, como fonte importante de informações e aprendizado. As entrevistas identificaram que essas fontes de informações apresentam baixos custos e de fácil acesso para as empresas cervejeiras. Em função disso, são utilizadas por praticamente todas as empresas para manterem-se atualizadas em relação às novidades de lançamento de matérias-primas com novas combinações, bem como o lançamento de novas máquinas e equipamentos que possibilitem adequações e melhoramentos nos processos de produção. 
Figura 4 - Grau de importância ${ }^{6}$ atribuído às fontes de informação para o aprendizado das empresas microcervejarias da região Noroeste do estado do Rio Grande do Sul - RS,

desempenhadas nos últimos três anos, 2014 a 2016

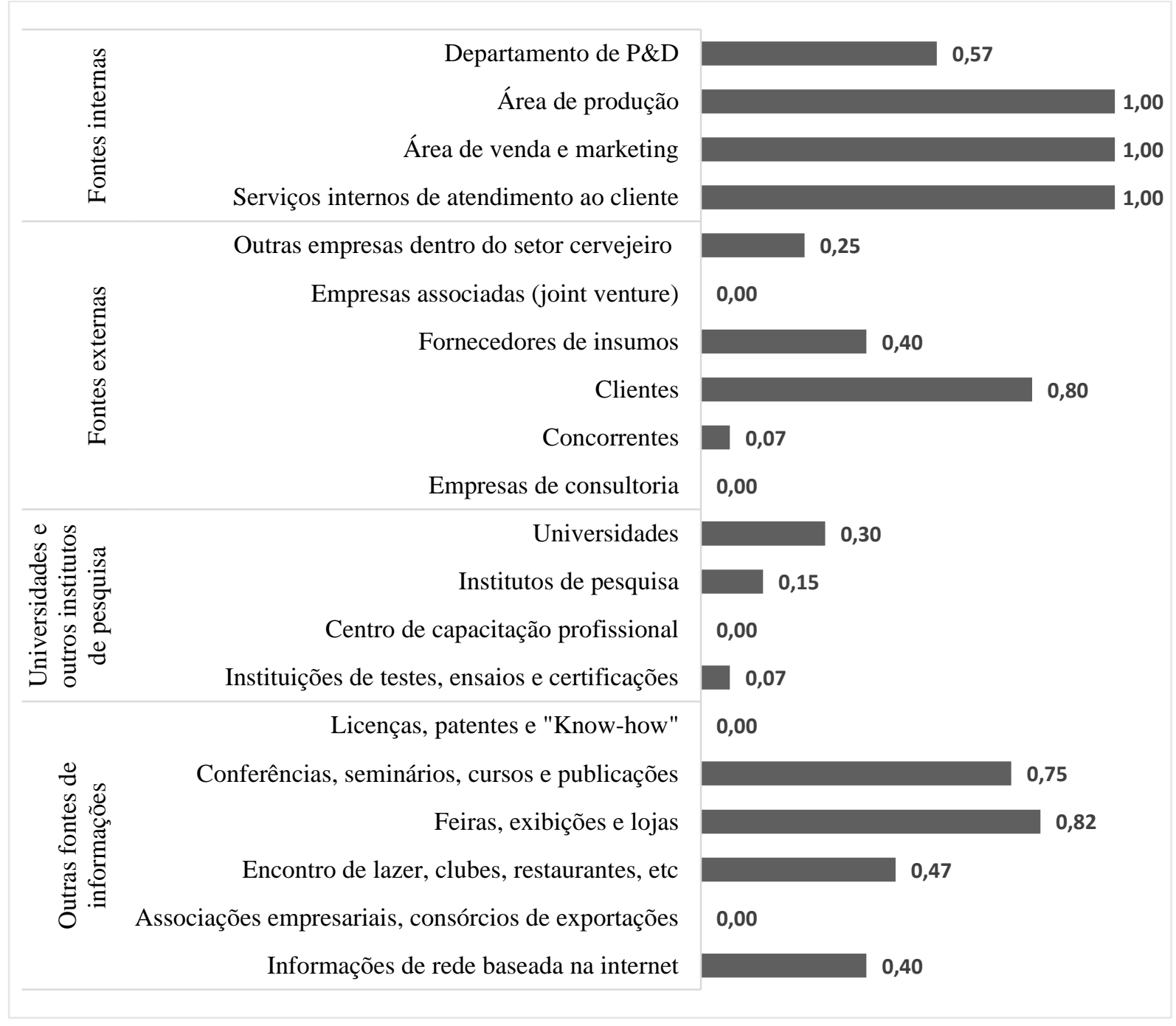

Fonte: Pesquisa de campo (2016)

Os investimentos em Pesquisa e Desenvolvimento (P\&D) foram identificados como de baixa importância pelas empresas. Já a aquisição de P\&D externa se dá através de parcerias com outras empresas do ramo como também fornecedores e especialistas, através de conversas, visitas, encontros sociais, geralmente informais, que agregam conhecimento e experiência. De forma geral, o P\&D interno acontece através do proprietário ou responsável pela organização e gerência da empresa, que se constituem nos maiores interessados em realizar pesquisas e desenvolver inovações que

${ }^{6}$ Grau de importância $=$ (Número de nulas * $0+$ Número de baixa * 0,30 + Número de média * 0,60 + Número de alta) / Número de empresas pesquisadas. 
potencializem os resultados da organização. Em todos os estabelecimentos pesquisados examinou-se que os proprietários elaboravam internamente testes para melhoramentos de suas receitas. Essas pesquisas envolvem testes com um cereal diferente, uma maturação em temperatura distinta para a criação de produtos diferenciados.

As firmas entrevistadas destacaram que existem alguns fatores considerados relevantes em relação à localização. A proximidade com o mercado consumidor e a infraestrutura local podem ser consideradas grandes vantagens em estar localizada na região Noroeste do Rio Grande do Sul. Contudo, essas vantagens não são decisivas para a presença das empresas na região. Além das vantagens citadas pode-se dizer que as firmas estão localizadas na região devido ao fato de que os sócios das empresas possuem outros empreendimentos no local, o que facilitou a construção de novos projetos.

Nas transações comerciais realizadas na região o destaque principal está relacionado à comercialização da produção. A pesquisa identificou que quase a totalidade da produção é vendida na própria região ou mesmo no próprio município em que está localizada a empresa, enquanto que as transações fora da região são bastante reduzidas.

Apesar da pesquisa ter constatado que existem limitações de recursos humanos qualificados na região em estudo, os empresários afirmam que existem pontos positivos na mão de obra local. Os pontos que apresentaram índices mais elevados foram a pontualidade, a disciplina, a capacidade de aprender novas técnicas e se qualificar, a flexibilidade, a criatividade e o empreendedorismo demonstrado pelos profissionais. Já o nível de escolaridade dos trabalhadores do setor não é alto, de modo que praticamente inexiste, nas firmas estudadas, profissionais com formação em cursos superiores. A partir das informações da RAIS (2017) essa característica segue o mesmo padrão demais microcervejarias no estado do Rio Grande do Sul.

Tendo em vista os argumentos apresentados durante a pesquisa, o esforço inovativo empreendido pelas empresas não possibilitou a redução dos custos de matéria-prima para a produção, uma vez que estes estão associados ao mercado externo. É considerado alto o nível de importância atribuído ao treinamento e à capacitação (vistos como indispensáveis), através de cursos técnicos, dentro do setor cervejeiro. A interação com fornecedores, clientes e mesmo com concorrentes possibilita a agregação de conhecimentos empíricos, os quais são fundamentais para o aumento da qualidade do produto. Pela observação dos aspectos analisados, a criação de políticas públicas de apoio a esse ramo de atividade foi sugerida pelas empresas do setor. Seria importante para o segmento de atividade cervejeiro a concessão de incentivos fiscais, linhas de crédito 
específicas para as suas necessidades, tais como financiamento para capital de giro e para aquisição de máquinas e equipamentos e iniciativas que ampliem a oferta de cursos de capacitação para gerar mão de obra qualificada destinada à atividade industrial cervejeira.

\section{CONSIDERAÇÕES FINAIS}

Esse estudo identificou os principais fatores que determinam a competitividade das microcervejarias da região Noroeste do estado do Rio Grande do Sul. A introdução de inovações tecnológicas ocorre ocasionalmente, mesmo assim as inovações introduzidas são importantes para o desenvolvimento das empresas. Verificou-se também que existe constante busca por novas formas de comercialização e distribuição. As empresas também procuram modernizar as suas organizações, promover treinamentos direcionados, introduzir produtos inovadores, novos projetos ou desenhos industriais. Neste contexto, a introdução de novas tecnologias é decisiva para a manutenção competitiva das empresas do ramo cervejeiro na região Noroeste do estado do Rio Grande do sul.

A pesquisa identificou que as empresas atribuem grande importância para os investimentos em inovações tangíveis, em especial a aquisição e modernização de máquinas e equipamentos. Enquanto os investimentos em inovações intangíveis, apesar de serem considerados importantes, são relegados a segundo plano. Esse aspecto está refletido no baixo nível de escolaridade da mão de obra utilizada pelas empresas e pela baixa importância atribuída às atividades de P\&D.

O principal fator determinante da competitividade, apontado pelas empresas, foi a qualidade da mão de obra que é empregada na produção da cerveja ou chopp, uma vez que o conhecimento aplicado ao processo produtivo é essencial para que o produto apresente a qualidade desejada pelo mercado consumidor. Os entrevistados também identificaram a assepsia dos equipamentos como elemento central para a conservação higiênica de todo o ambiente de produção, fermentação e envase do produto. Em última análise esses elementos são fundamentais para garantir a qualidade da bebida.

A força de trabalho também foi apontada como determinante dos processos de aprendizagem das microcervejarias e do desenvolvimento do setor propriamente dito. $\mathrm{O}$ treinamento de recursos humanos, no interior da empresa, somado ao feedback oriundo dos clientes foram apontados como os principais elementos que contribuem para 0 aperfeiçoamento da produção, bem como para a acumulação de conhecimento das 
empresas. Estes esforços de aprendizado foram considerados essenciais para a qualidade e aceitação dos produtos. As capacitações realizadas com os profissionais envolvem desde o processo produtivo até a maneira adequada de atender o cliente, com o objetivo de criar vínculos de fidelidade com o consumidor para que ele continue a demandar o produto.

Verificou-se, também, um considerável esforço inovativo realizado pelas empresas durante os últimos anos. A principal ação realizada pelas empresas foi a aquisição de equipamentos mais modernos e eficientes para a produção em maior escala, com maior grau de flexibilidade. Esse esforço inovativo favoreceu a ampliação da quantidade produzida e da qualidade geral do produto.

As empresas também realizaram inovações organizacionais e de suas rotinas administrativas. Essas inovações permitiram melhoramentos no atendimento ao cliente e redução considerável em alguns custos administrativos e produtivos. As empresas enfatizaram as suas aquisições de equipamentos mais modernos, que contribuíram para tornar a produção mais eficiente e rentável, uma vez que diminuíram, consideravelmente, a necessidade do trabalho humano na parte de produção, ou seja, aumentaram a produtividade do capital empregado.

Em resumo, as empresas entrevistadas realizam grande esforço inovativo para competir com cervejas tradicionais e veem no mercado consumidor crescente a sua principal vantagem competitiva local. Concluiu-se, também que a agregação de valor aos produtos ocorre sem ajuda de agentes externos, apenas com o esforço das próprias empresas, que conseguem evoluir e ampliar suas linhas de produção.

\section{REFERÊNCIAS}

AFEBRAS. Associação dos Fabricantes de Refrigerantes do Brasil. Disponível em: http://afrebras.org.br/setor/bebidas-alcoolicas/composicao-de-mercado. Acesso em: 09 de abril de 2016.

BELL, M.; PAVITT, K. Technological accumulation and industrial growth: contrasts between developed and developing countries. Industrial and Corporate Change, n. 2, 1993.

CARVALHO, G. D. G.; NASCIMENTO, D. E.; STRAUHS, F. R.; CARVALHO, H. G.; CRUZ, J. A. W. O papel da cooperação para a inovação em micro e pequenas empresas do estado do Paraná. Revista Brasileira de Gestão e Desenvolvimento Regional, v. 12, p. 419-442, 2016. Disponível em: https://www.rbgdr.net/revista/index.php/rbgdr/article/view/2531. Acesso em: 15 jun 2019. 
CERVBRASIL. Associação Brasileira da Indústria da cerveja. Disponível em: http://www.cervbrasil.org.br/paginas/index.php?page=mercado-cervejeiro. Acesso em: mar. de 2016.

CERVESIA. Soluções em tecnologia cervejeira e gestão de processos. Disponível em: http://www.cervesia.com.br/dados-estatisticos.html. Acesso em: 08 abr. 2016.

FREEMAN, C., SOETE, L. A economia da inovação industrial. Campinas: Editora da Unicamp, 2008.

GIORGI, Victor de Vargas. A "cultura cervejeira" em Ribeirão Preto (1996-2016): entre uma prática transformadora e um recurso conservador. 2017. 183 f. Dissertação (Mestrado em História) - Universidade Federal de Uberlândia, Uberlândia, 2017.

GOIA, M. R.; CHAVES, R. L. P. Cerveja Artesanal Carioca: A Fabricação de uma Cultura. Revista ADM.MADE, v. 20, n. 2, p. 56-71, 2017.

HOBSBAWM, E. Introduction: Inventing Traditions. In: HOBSBAWM, E.; (EDS.), T. R. The Invention of Tradition. Cambridge: Cambridge University Press, 2013.

LAGES, M. P. A formação do consumo gourmet no Brasil: o caso dos cafés especiais e dos corpos que os acompanham. 2015. 184 f., il. Dissertação (Mestrado em Sociologia) —Universidade de Brasília, Brasília, 2015.

LIMBERGER, S. C.; TULLA, A. A emergência de microcervejarias diante da oligopolização do setor cervejeiro (Brasil e Espanha). Finisterra, Lisboa, n. 105, p. 93110, ago. 2017. Disponível em http://www.scielo.mec.pt/scielo.php?script=sci_arttext\&pid=S0430$50272017000200006 \&$ lng=pt\&nrm=iso. Acesso em 15 jul. 2019.

LUNDVALL, B. Innovation as an interactive process from user-producer interaction to the national system of innovation. In: DOSI, G. et al. (Ed.). Technical change and economic theory. London: Pinter, 1988.

MAIER, T. Sources of Microbrewery Competitiveness in the Czech Republic. AGRIS online Papers in Economics and Informatics, v. 8, n. 4, p. 97-110. 2016.

MAIER, T. Selected Aspect of the Microbreweries Boom. AGRIS on-line Papers in Economics and Informatics, v. 5, n. 4, p. 135-142. 2013.

MALERBA, F. Learning by firms and incremental technical change. The Economic Journal, v. 102, n. 413, p. 845-859, Jul. 1992.

MALERBA, F., CALOGHIROU, Y., MCKELVEY, M.D; RADOSEVIC, S. Dynamics of Knowledge Intensive Entrepreneurship: Business Strategy and Public Policy. London, U.K.: Routledge, 2015.

MCKELVEY, M; ZARING, O. SZUCS, S. Governance of Regional Innovation Systems: An Evolutionary Conceptual Model of How Firms Engage. DRUID15, Rome, June 15-17, 2015. 
MORADO, R. Larousse da cerveja. São Paulo. Larousse do Brasil, 2009.

RAIS. Relação Anual de Informações Sociais. Mistério do Trabalho e do Emprego. Disponível em: http://bi.mte.gov.br/bgcaged/. Acesso em: 02 mar. 2016.

REDESIST. Rede de pesquisa em sistemas e arranjos produtivos e inovativos locais. Disponível em: http://www.redesist.ie.ufrj.br/resultados/publicacoesquestionarioapls. Acesso em: 24 mar. de 2016.

REGIS, S. V. C.; PEREIRA, Y. V.; SALAZAR, V. S. Cervejas Artesanais e a Experiência de Consumo do Nordestino Brasileiro. Temática, NAMID-UFPB, Ano XIII, n. 6, p. 34-50, jun. 2017.

RITA, L. P. S.; SOUZA, W. A. R.; ZANCAN, C.; FERREIRA JUNIOR, R. R.; DANTAS, ANDERSON DE BARROS. Avaliação do sistema setorial de inovação - SSI: análise da indústria química de alagoas. Revista Brasileira de Gestão e Desenvolvimento Regional, v. 12, p. 27-59, 2016. Disponível em:

https://www.rbgdr.net/revista/index.php/rbgdr/article/view/2512. Acesso em 15 jun. 2019.

SCHUMPETER, J. A. Teoria do desenvolvimento econômico: uma investigação sobre lucros, capital, crédito, juro e o ciclo econômico. São Paulo: Nova Cultural, 1988.

SCHWARTZ, D.; BAR-EL, R. The role of a local industry association as a catalyst for building an innovation ecosystem: An experiment in the State of Ceara in Brazil.

Innovation: Management Policy \& Practice, v. 17, n. 3, p. 383-399, 2015.

SEBRAE. Serviço Brasileiro de Apoio às Micro e Pequenas Empresas. Demanda de Consumo. Disponível em:

http://www.sebrae.com.br/sites/PortalSebrae/artigos/Microcevejarias-ganham-espaço-nomercado-nacional. Acesso em 08 de abril de 2016.

SIMANTOB, M.; LIPPI, R. Guia Valor Econômico de Inovação nas Empresas. São Paulo: Ed. Globo, 2003.

STEFENON, R. Vantagens competitivas sustentáveis na indústria cervejeira: o caso das cervejas especiais. Revista Capital Científico - Eletrônica, v. 10, n. 1, p. 1-16, 2012. 


\section{NOTAS DA OBRA}

\section{CONFLITO DE INTERESSES}

Não se aplica.

\section{LICENÇA DE USO}

Os autores cedem à Textos de Economia os direitos exclusivos de primeira publicação, com o trabalho simultaneamente licenciado sob a Licença Creative Commons Attribution Non-Comercial ShareAlike (CC BY-NC SA) 4.0 International. Esta licença permite que terceiros remixem, adaptem e criem a partir do trabalho publicado, desde que para fins não comerciais, atribuindo o devido crédito de autoria e publicação inicial neste periódico desde que adotem a mesma licença, compartilhar igual. Os autores têm autorização para assumir contratos adicionais separadamente, para distribuição não exclusiva da versão do trabalho publicada neste periódico (ex.: publicar em repositório institucional, em site pessoal, publicar uma tradução, ou como capítulo de livro), com reconhecimento de autoria e publicação inicial neste periódico, desde que para fins não comerciais e compartilhar com a mesma licença.

PUBLISHER Universidade Federal de Santa Catarina. Departamento de Economia e Relações Internacionais. Publicado no Portal de Periódicos UFSC. As ideias expressadas neste artigo são de responsabilidade de seus autores, não representando, necessariamente, a opinião dos editores ou da universidade.

\section{EDITORES -}

Solange Regina Marin 